\title{
Dental Bleaching- Case Report \& Review
}

Dr. Sudhakar Srinivasan MDS ${ }^{1 *}$, Dr. Gayathri Velusamy MDS $^{2}$, Dr. Karthikeyan Radhakrishnan MDS ${ }^{3}$, Dr. Munshi MAI MDS ${ }^{4}$, Dr. Sushil Bhagwan Mahajan ${ }^{5}$, Dr. Shazia Salim ${ }^{6}$

${ }^{1}$ Conservative Dentistry \& Endodontics, Associate Professor, Karpagam Faculty of Medical Sciences and Research, Coimbatore, Tamil Nadu, India

${ }^{2}$ Conservative Dentistry \& Endodontics, Senior Lecturer, Sri Ramakrishna Dental College and Hospital, Coimbatore, Tamil Nadu, India

${ }^{3}$ Pedodontics, Senior Lecturer, Sri Ramakrishna Dental Colllege and Hospital, Coimbatore, Tamil Nadu, India

${ }^{4}$ Oral and Maxilolofacial Surgery, Reader, Sri Ramakrishna Dental Colllege and Hospital, Coimbatore, Tamil Nadu, India

${ }^{5}$ 2nd Yr Mds Orthodontics and Dentofacial Orthopedic, Dr. H.S.R.S.M. Dental College and Hospital Hingoli, Maharashtra India

${ }^{6}$ Assistant Professor, Department of Conservative Dentistry and Endodontics, Mahe Institute of Dental Sciences and Hospital, Pondicherry University Kerala India

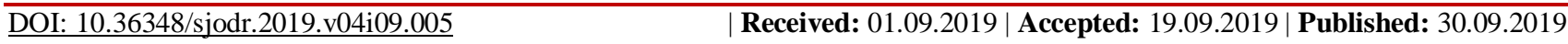

*Corresponding author: Dr. Sudhakar Srinivasan

\section{Abstract}

A blight white smile has always been a symbol of health, beauty and vitality for hundreds of years. Discoloration of the front teeth causes a significant disturbance in the aesthetics and may also decrease the patient's self-esteem. Public demand for the aesthetic dentistry which includes the tooth whitening has increased in recent years. Dental bleaching offers a simplified, conservative and low cost approach to change the color of discolored teeth. The pigments oxidation is responsible for tooth bleaching and can be carried out with two different products; carbamideperoxide and hydrogen peroxide. The present case reports reflect a remarkable change of tooth color by in-office bleaching.

Keywords: Dental bleaching, hydrogen peroxide, in-office bleaching.

Copyright @ 2019: This is an open-access article distributed under the terms of the Creative Commons Attribution license which permits unrestricted use, distribution, and reproduction in any medium for non-commercial use (NonCommercial, or CC-BY-NC) provided the original author and source are credited.

\section{INTRODUCTION}

A beautiful smile is desired by all. A beautiful smile comprises not only perfect sizes and the shapes, but also color. Many things of a person are revealed by the tooth color such as oral health, good or bad habits and their age. Since everyone wants to look young and well maintained, tooth whitening has become one of the most desired and performed cosmetic dentistry procedures. However, the treatment is scientifically proven and safe, some precautions must be taken. Many whitening products are available in the market. Each product was developed for specific scenarios, because every patient is different. The cosmetic dentistry has developed many techniques and several ways to change the color of teeth, in order to make the treatment more comfortable, painless, predicable and achieving long lasting results [1]. Tooth whitening also called as dental bleaching, is a common procedure comes under general dentistry. In contrast to the invasive treatments, such as veneers or crowns, bleaching is a conservative and noninvasive procedure. There are many methods, such as brushing, bleaching pen, bleaching strips, bleaching gel and laser bleaching which are available nowadays. In today's world of cosmetic dentistry, teeth whitening have become the most requested procedure [2]. There are mainly two types of whitening /bleaching procedures-i) Non-vital whitening is done on a tooth that has had root-canal treatment and no longer a vital tooth and ii) Vital whitening is performed on the teeth that are vital. The gel like whitening solution is the most commonly used for the vital tooth whitening and is applied directly to the surface of the tooth. This product contains some form of hydrogen peroxide [3]. Vital bleaching is an in-office procedure and high concentration hydrogen peroxide most popularly used for the in-office bleaching and are often referred to as "one-hour bleaching". The high concentration hydrogen peroxides range from $25 \%$ to $35 \%$. The in-office bleaching can be provided either in one-visit of 1-1.5 hour treatment or in a multiple visit procedure [1-3]. Light- enhanced systems can be used for the in-office bleaching. There are certain safety protocols to be followed in order to use the high concentration hydrogen peroxide gels intraorally. First, the doctor as well as the patient must wear the eye protection, and also a barrier must be placed on the gingival soft tissues adjacent to the procedure. Moreover, some types of lights generate heat and or UV rays, thus, a rubber dam napkin is used in order to shield the face from the light source. In some cases, the manufacturers provide the moisturizers for the lips or sun screen as the protection from UV rays. However, a dental dam would be ideal 
but the placement of a dental dam will inhibit the bleaching of cervical areas of the teeth, which will dissatisfy patients. In order to overcome this problem, the manufacturers have provided the barrier protection in the form of a light cured resin that is painted over the gingival tissues $[2,3]$.

\section{REPORT OF 2 CASES}

Two female patients reported with the chief complaint of discoloration of teeth. The key clinical parameters that are focused during the examination were no or minimal gingival recession, good periodontal health and the absence of decay. Moreover, the questions about any history of tooth sensitivity were asked. The importance of asking this is that patient who has a history of tooth sensitivity may also occasionally experience the mild to moderate tooth sensitivity for 24 hours after the in-office bleaching. In the present report, both the cases had no history of any tooth sensitivity. Pre-operative photos were taken (Figure-1\& 2).

Dental bleaching was done for both the patients by using 35\% hydrogen perioxide, which facilitates a significant whitening procedure with a total time from start to finish of less than one hour. The shorter treatment duration and the inclusion of potassium nitrate in the composition, provides the patients with less treatment and/or post-operative sensitivity than other in-office systems.

The patient was asked to return in 10 days to evaluate the results. Using standard visual examination and confirmation, a noticeable shade change has occurred (Figure 3\&4). The patient noticed a marked improvement and was very pleased with the final outcome.

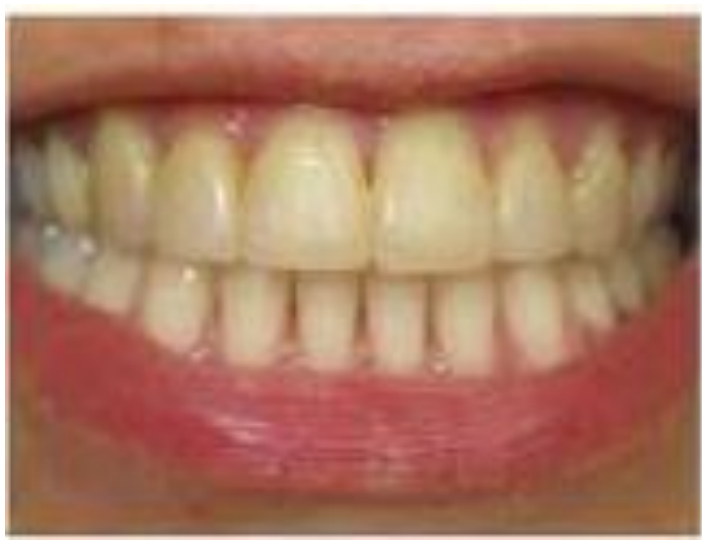

Fig-1: Case I - Before Bleaching

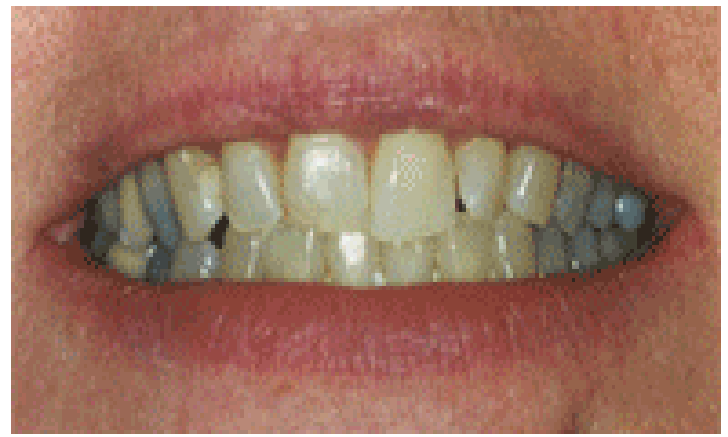

Fig-2: Case II - Before Bleaching

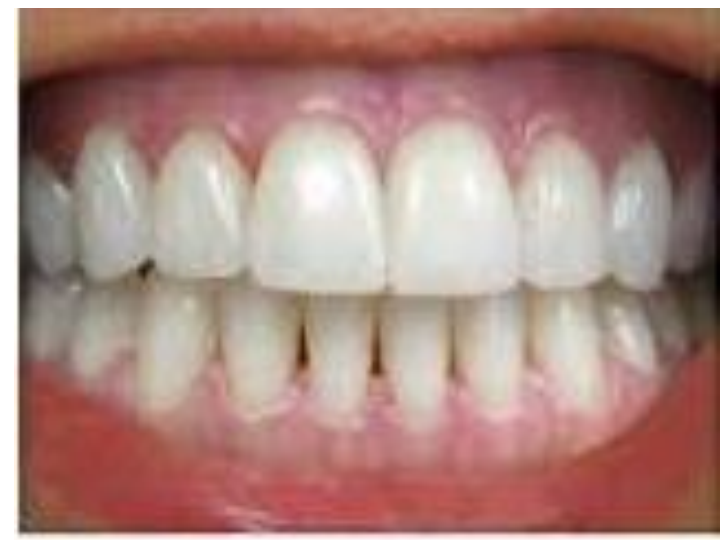

Fig-3: Case I - After Bleaching

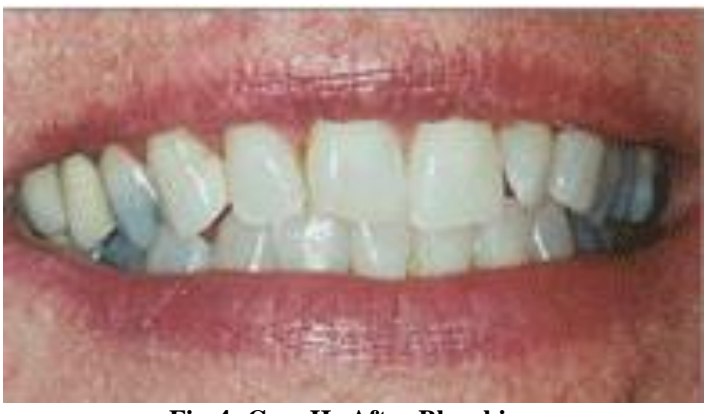

Fig-4: Case II- After Bleaching

\section{DISCUSSION}

There are several esthetic treatment options which are available in the field of dentistry and bleaching is one of them [4]. The combination of intrinsic color of the tooth and external stain are responsible for the color of the tooth $[5,6]$. Dentin has major role in the intrinsic tooth color because of the properties like light absorption and scattering [7, 8] The extrinsic stains tend to form usually in the areas of teeth which are less accessible to the cleaning by toothbrush and also associated with adverse habits like smoking, tobacco chewing, dietary intake of tannin-rich foods (e.g. red wine, tea) and the use of certain cationic agents such as chlorhexidine, or metal salts such as iron and tin $[9,10]$. Several methods are there in order to remove the surface discoloration which includes the whitening toothpastes, scaling, polishing, micro abrasion of enamel, bleaching, veneers, crowns etc $[11,12]$. Various brands of bleaching agents with several 
concentrations are available in the today's market. In order to perform the in-office bleaching, both appropriate isolation and adequate protection of the mucosal tissues are necessary. The understood mechanism of tooth bleaching by hydrogen peroxide $\left(\mathrm{H}_{2} \mathrm{O}_{2}\right)$ is the diffusion of free radicals produced by hydrogen peroxide $\left(\mathrm{H}_{2} \mathrm{O}_{2}\right)$ through the enamel and the dentin, which then interact with the pigment and causes the whitening effect on the teeth. These free radicals break down the double bond between the pigment molecules and change its configuration. Because of this change in the configuration, the optical properties of tooth get change and the tooth appears whiter [13]. Apart from the action of radicals, few other factors responsible for tooth whitening are cleaning and polishing before and after the bleaching procedure as well as the dehydration of the tooth by bleaching agent which makes tooth whiter [14]. The final outcome of the bleaching is influenced by various factors such as patient's age, original shade of tooth color, concentration of bleaching agent and the time for which the bleaching agent has been exposed to tooth surface $[15,16]$. The dentists may also consider for prescribing the NSAIDs prior to the treatment because the posttreatment sensitivity is unpredictable. The treatment schedule is also a useful method in order to minimize the tooth sensitivity. Typically, multiple appointments are scheduled one week apart to allow sensitivity to abate. Sometimes, a "bleaching light" is used for inoffice bleaching procedures as well. Some reports have suggested that the pulpal temperature can increase with the use of bleaching light, depending upon the light source and the exposure time. According to an in vitro study, it has been suggested that the usage of some lights may result in light radiation exposure levels approaching or exceeding the safety limits [17]. Tooth sensitivity and pulpal irritation may be higher with use of bleaching lights or heat application, and therefore, the caution has been advised with their use [18, 19] However, there have been many in vitro studies conducted comparing the effectiveness of in-office bleaching with or without light application and the result had conflicting evidence on the effects of bleaching lights on the change in tooth color. There was variability in the effects on tooth color change, and some differences which were detected digitally were not visually detectable. Similar observation was reported in a recent clinical study report as well [20]. Among the studies conducted in vivo, there was no added benefit found for the light activated systems [21]. There may be initial increase in the whitening by the light and heat application due to greater dehydration which gradually reverses with time. The actual change in the color will not be evident till 2 to 6 weeks after the bleaching treatment. The average number of the inoffice visits in order to get the outcome for maximum whitening is three [22] with a range of 1 to 6 visits, thus the patient should be prepared for additional in-office treatments [23]. Dental bleaching or tooth whitening can be a very effective way for lightening the natural color of teeth without removing any of the tooth surfaces. Although, it cannot completely change the tooth color but it may lighten the existing shade of tooth. In today's world, the society has been influenced by the picture perfect white smiles. Nowadays, selfawareness of discolored teeth has risen greatly among the population. There are advantages as well as disadvantages of the INS office bleaching procedure [24]. The advantages are faster bleaching procedure, the procedure is under professional and therefore the risk factor is eliminated and the tooth sensitivity is less because of the use of desensitizers such as fluoride and potassium nitrate. Whereas the disadvantages are that the INS office bleaching procedure is most expensive than the other bleaching procedure, the results can be unpredictable and depend on various factors like type of stain, age etc.

\section{CONCLUSION}

Dental bleaching is an effective treatment modality that can change the appearance of teeth significantly. After the use of professionally dispensed bleaching therapy, the patient satisfaction has been demonstrated. Based upon the clinical results which are reported with the professional vital tooth bleaching, it can be considered as a viable aesthetic treatment for the discolored teeth. The in-office bleaching treatment has gained a lot of popularity among the general public. Moreover, many patients are now aware about the inoffice bleaching procedure that many dentists offer and it is a great procedure in order to get a fast result in whitening of their teeth. In the today's world of immediate gratification, the in-office bleaching is one of the most requested procedures in dental offices.

\section{REFERENCES}

1. Dahl, J.E., Pallesen, U. (2003). Tooth Bleaching-A critical review of the biological aspects. Crit Rev Oral Biol Med, 14(4): 292-304

2. Luk, K., Tam, L., Hubert, M. (2004). Effect of light energy on peroxide tooth bleaching. J Am Dent Assoc, 135(2):194-201.

3. Haywood, V. B. (2006). Number of in-office lightactivated bleaching treatments needed to achieve patient satisfaction. Quintessence Int, 37, 115-120.

4. Mulay, S., \& Band, A. (2014). Comparative Evaluation of Two in-Office Bleaching Agents Using Two Different Light Sources-In Vivo Study. J Dent Med.

5. Watts, A., \& Addy, M. (2001). Tooth discolouration and staining: tooth discolouration and staining: a review of the literature. British dental journal, 190(6), 309.

6. Joiner, A. (2004). Tooth colour: a review of the literature. Journal of dentistry, 32, 3-12.

7. Ten Bosch, J. J., \& Coops, J. C. (1995). Tooth color and reflectance as related to light scattering and enamel hardness. Journal of dental research, 74(1), 374-380. 
8. Muia, P.J. (1985). The four dimensional tooth color system. Chicago: Quintessence Publishing Co. Inc.

9. Nathoo, S. (1997). The chemistry and mechanisms of extrinsic and intrinsic discoloration. Journal of the American Dental Association, 128:6S-10S.

10. Joiner, A., Jones, N.M., Raven, S.J. (1995). Investigation of factors influencing stain formation utilizing an in situ model. Advances in Dental Research, 9:476.

11. Sarrett, D.C. (2002). Tooth whitening today. Journal of the American Dental Association, 133:1535-8

12. Berman, L. H. (1982). Intrinsic staining and hypoplastic enamel: etiology and treatment alternatives. General Dentistry, 484-8.

13. Linda dyett. In office teeth whitening professional advantages, option and cost. Consumer guide to dentistry.

14. Li, Y. (2011). Safety controversies in tooth bleaching. Dent Clin N Am, 55: 255-263.

15. Tavares, M., Stultz, J., Newman, M., Smith, V., Kent, R., Carpino, E., \& Goodson, J. M. (2003). Light augments tooth whitening with peroxide. The Journal of the American Dental Association, 134(2), 167-175.

16. Li, Y., Lee, S. S., Cartwright, S. L., \& Wilson, A. C. (2003). Comparison of clinical efficacy and safety of three professional at-home tooth whitening systems. Compendium of continuing education in dentistry (Jamesburg, NJ: 1995), 24(5), 357-60.

17. Charakorn, P., Cabanilla, L. L., Wagner, W. C., Foong, W. C., Shaheen, J., Pregitzer, R., \&
Schneider, D. (2009). The effect of preoperative ibuprofen on tooth sensitivity caused by in-office bleaching. Operative dentistry, 34(2), 131-135.

18. Bruzell, E. M., Johnsen, B., Aalerud, T. N., Dahl, J. E., \& Christensen, T. (2009). In vitro efficacy and risk for adverse effects of light-assisted tooth bleaching. Photochemical \& Photobiological Sciences, 8(3), 377-385.

19. Buchalla, W., \& Attin, T. (2007). External bleaching therapy with activation by heat, light or laser-a systematic review. Dental materials, 23(5), 586-596.

20. Baik, J. W., Rueggeberg, F. A., \& Liewehr, F. R. (2001). Abstract. Journal of Esthetic and Restorative Dentistry, 13(6), 370-378.

21. Gurgan, S., Cakir, F. Y., \& Yazici, E. (2010). Different light-activated in-office bleaching systems: a clinical evaluation. Lasers in medical science, 25(6), 817-822.

22. Kugel, G., Papathanasiou, A., Anderson, C., \& Ferreira, S. (2006). Clinical evaluation of chemical and light-activated tooth whitening systems. Compendium of continuing education in dentistry (Jamesburg, NJ: 1995), 27(1), 54-62.

23. Auschill, T. M., Hellwig, E., Schmidale, S., Sculean, A., \& Arweiler, N. B. (2005). Efficacy, side-effects and patients' acceptance of different bleaching techniques (OTC, in-office, athome). Oper Dent, 30(2), 156-63.

24. Matis, B. A., Cochran, M. A., Wang, G., \& Eckert, G. J. (2009). A clinical evaluation of two in-office bleaching regimens with and without tray bleaching. Operative dentistry, 34(2), 142-149. 